\title{
Hidden analyses: A review of current reporting practice and recommendations for more transparent reporting of initial data analyses
}

Marianne Huebner ( $\sim$ huebner@msu.edu )

Michigan State University https://orcid.org/0000-0002-9694-9231

Werner Vach

Universitatsspital Basel

Saskia le Cessie

Universiteit Leiden Medical Center

Carsten Oliver Schmidt

Universitatsmedizin Greifswald

Lara Lusa

University of Primorksa

Research article

Keywords: Initial data analysis, reporting, observational studies, STRATOS Initiative

Posted Date: December 16th, 2019

DOI: https://doi.org/10.21203/rs.2.18728/v1

License: (c) (i) This work is licensed under a Creative Commons Attribution 4.0 International License. Read Full License

Version of Record: A version of this preprint was published at BMC Medical Research Methodology on March 13th, 2020. See the published version at https://doi.org/10.1186/s12874-020-00942-y. 


\section{Abstract}

Background: In the data pipeline from the data collection process to the planned statistical analyses, initial data analysis (IDA) typically takes place between the end of the data collection and do not touch the research questions. A systematic process for IDA and clear reporting of the findings would help to understand the potential shortcomings of a dataset, such as missing values, or subgroups with small sample sizes, or shortcomings in the collection process, and to evaluate the impact of these shortcomings on the research results. A clear reporting of findings is also relevant when making datasets available to other researchers. Initial data analyses can provide valuable insights into the suitability of a data set for a future research study. Our aim was to describe the current practice of reporting of initial data analyses in observational studies in five highly ranked medical journals with focus on data cleaning, screening, and reporting of findings which led to a potential change in the analysis plan.

Methods: This review was carried out using systematic search strategies with eligibility criteria for articles to be reviewed. A total of 25 papers about observational studies were selected from five medical journals. Each paper was reviewed by two reviewers and IDA statements were further discussed by all authors. The consensus was reported.

Results: IDA statements were reported in the methods, results, discussion, and supplement of papers. Ten out of 25 papers (40\%) included a statement about data cleaning. Data screening statements were included in all articles, and 18 (72\%) indicated the methods used to describe them. Item missingness was reported in 11 papers (44\%), unit missingness in 15 papers (60\%). Eleven papers (44\%) mentioned some changes in the analysis plan. Reported changes referred to missing data treatment, unexpected values, population heterogeneity and aspects related to variable distributions or data properties.

Conclusion: Reporting of initial data analyses were sparse, and statements on IDA were located throughout the research articles. There is a lack of systematic reporting of IDA. We conclude the article with recommendations on how to overcome shortcomings in the current practice of IDA reporting in observational studies.

\section{Background}

Much discussion has focused on selective reporting based on statistical significance and $p$-values in research. An overemphasis on statistical significance possibly led to spurious results in medical research (1). However, p-values are only the "tip of the iceberg" in a long data pipeline that includes data cleaning, data screening or exploratory data analysis, before the statistical modelling takes place (2). A typical part of this data pipeline may be referred to as Initial Data Analysis (IDA). IDA typically takes place between the end of the data collection and the start of those statistical analyses that address the research questions, although some IDA aspects may occur already during the data collection process.

A recently introduced IDA framework distinguished six IDA steps (3). The first step is to set up the meta data, which includes all background information required to properly conduct subsequent IDA steps. In 
the next two steps, the data should be systematically cleaned and screened. Data cleaning aims to identify data errors and, if possible, correct them. Data screening systematically reviews and documents data properties and data quality that may affect future analysis and interpretation (step 3). Careful reporting of all relevant insights obtained from the cleaning and screening steps is needed to inform researchers who work with the data (step 4). Data properties may not conform to our subject knowledge that was used to develop the analysis plan. For example, the distribution of some variables is unexpectedly skewed, more values are missing than expected, or data errors are detected. In that case it may be necessary to refine or update the analysis plan (step 5). The final step of IDA is the reporting relevant findings of IDA in research papers to document all findings and analytic choices that impact the interpretation of results.

Wasserstein et al (4) coined the term ATOM (Accept uncertainty, be Thoughtful, Open, and Modest.) for good research practice. Conducting IDA can contribute to good research practice and is related to the ATOM principles. Thoughtful research begins with clear objectives, and these objectives are part of the meta data. Subsequent IDA steps aim to provide reliable knowledge about the data to enable responsible statistical analyses and interpretation. Reporting all relevant findings of the IDA and any update of the analysis plan which may be revealed during IDA, contributes to the necessary openness in research. Furthermore, IDA may point to limitations of the data, which when reported, contribute to accepting uncertainty.

Completeness in reporting requires not only the description of limitations of the data, but also a description of the initial analyses performed and presenting the findings thus obtained. Yet, IDA is often "hidden" in the sense that analyses and subsequent decisions are often conducted in an unplanned and unstructured way, only partially shared among research collaborators or described in research papers. Failing in reporting can lead to publication bias (5) or invalid results (6).

It is reasonable to expect that not all elements of IDA will be reported in a published research article because of the large scope of IDA relative to common space restrictions. The reporting guideline for observational studies STROBE statement (7) considers some aspects of IDA reporting. This consists of the description of baseline and outcome variables or the reporting of missing values in variables and numbers of missing individuals at each stage of study. However, this may not inform the reader completely about all relevant IDA results and decisions make in the IDA steps. Our aim was to describe current practice of IDA reporting in observational studies in five highly ranked medical journals with focus on data cleaning, screening, and reporting of findings which led to updating the analysis plan. We conclude the article with recommendations on how to overcome short comings in the current practice of IDA reporting in observational studies.

\section{Methods}

This was a methodological study with an a priori protocol. The review was carried out using systematic search strategies with eligibility criteria for articles to be reviewed. Reporting adhered to the PRISMA 
guidelines. To aid transparency, the search strategy and data collection form are available on the STRATOS TG3 website (https://www.stratosida.org/activities/project-systematic-review-of-ida-reporting) and are included in the supplement.

\section{Sampling Frame}

Papers were selected from five medical journals (The New England Journal of Medicine (NEJM), Lancet, Journal of Clinical Oncology (JCO), Circulation (CIRC), Journal of the American Medical Association (JAMA)). All papers published in a six-month window from January 2018 to July 15, 2018 meeting the inclusion criteria were included. The primary reviewer $[\mathrm{MH}]$ screened the titles and abstracts against the inclusion criteria. Full reports were obtained of all articles which appeared to meet the inclusion criteria. Each statement in a selected paper needed to be carefully evaluated regarding its relation to initial data analysis. Thus for an equal representation across journals five papers from each journal were randomly selected and reviewed by two reviewers. For each journal selected papers were ordered, then the order was permuted using the statistical software $\mathrm{R}$, and the first 5 papers on the list were selected. If, upon examination, an article did not meet the inclusion criteria, it was replaced by the next paper on the list from the target journal.

\section{Inclusion criteria}

- Observational study, original research articles

- Published in one of the selected journals and available between January 2018 and July $15^{\text {th }}, 2018$ (including Epub ahead of print).

\section{Exclusion criteria}

- Clinical trials, randomized experiments, laboratory studies, genetics or genomics studies, letters, editorials, reviews, guidelines, comments

- Fewer than 50 participants

- Simulation studies, imaging studies, cost studies

- Studies published only in abstract form

- No clear research aim stated (This was necessary to separate IDA from the planned statistical analyses.)

A flow chart of study selection was created and characteristics of the included studies were summarized.

\section{Data extraction}

Data were extracted from the selected papers using a standardized data extraction form developed for this review. An online submission form was prepared, piloted and refined prior to use by two authors LL and $\mathrm{MH}$. This was based on the conceptual framework for IDA (3) which was developed for studies including a primary data collection, but major parts of the framework apply also to studies based on a 
secondary data analysis. The form included data on study background (author, country, sample size, data source), elements of IDA framework reported (data cleaning, screening, change in the analysis plan). Each aspect was classified by the location in the paper where the respective aspect was targeted and ranked by sufficiency of information (not mentioned, mentioned, mentioned with sufficient detail or not applicable). Text excerpts from the articles could be added in the form. Information was requested separately for the outcome variable(s) according to the main research question. Other variables were labeled as "non-outcome variables." Information on statistical methods that were used to describe variables and their placing in the paper, was also collected. The reporting of missing values was assessed. We distinguished item missingness as data values partially missing from unit missingness, which referred to complete missingness of measurements from observational units (e.g. no observations for an individual at a certain time point).

The full articles were reviewed, and the location of IDA statements was noted as Introduction, Methods, Results, Discussion, and Supplement. If topics were mentioned in more than one section, the main selections were reported and therefore the sum of reported locations could exceed the sample size of 25 articles.

All co-authors reviewed at least five papers, with $\mathrm{MH}$ reviewing all papers to assure consistency in applying criteria. In this paper we report the consensus between two reviewers.

\section{Data analysis}

Both quantitative summaries and qualitative evaluation of text excerpts were employed. Each extracted item was summarized overall and by location in the article. A summary stratified by journal was not attempted due to the small number of articles from each journal.

After the initial inspection of the extracted text excerpts it became clear that different reviewers had different interpretations of the distinction between "sufficient "and "mentioned." It was therefore decided to collapse these terms.

The mapping of the text excerpts to one or possible multiple IDA elements was discussed in several meetings (in person or online) by all co-authors until agreement was reached.

\section{Results}

A total of 192 candidate articles were identified in the five journals for the time period January 1 to July 15, 2018 in the five journals (TABLE 1). A total number of 25 articles were included in this review (FIGURE 1, TABLE 1).

\section{See Figure 1}

Data sources for these observational studies included national registries, health insurance data bases, or health records from a single or multiple hospitals or cohort studies (TABLE 2). 
Twelve of the 25 studies were based in the USA. Studies had large sample sizes (median = 11,422 participants, IQR: 1,850 to 144,816$)$. Survival endpoints $(19 / 25)$ or binary outcomes $(5 / 25)$ were the most common outcomes.

\section{Reporting of initial data analyses}

\section{Data cleaning}

Ten out of 25 papers (40\%) included a statement about data cleaning. The statements were often general as illustrated by the following examples:

- “Clinically improbable laboratory values were removed." (10)

- "The statistical analysis was performed on the data entered, checked, if necessary corrected and validated by the centers. " (28)

- "Registrars were asked to follow-up with outside institutions in an effort to try to ensure data completeness, but actual data completeness was not measured." (11)

No sufficient information about the nature of the problems encountered in data cleaning, or the number of records for which errors were detected and corrected was reported. Consequently, even if data cleaning was mentioned, we often know little about the process and potential impact. More details were provided, when explicitly reporting the rules for correcting data values, or reporting the range of admissible values and number of records with values outside the range in the Supplement (10). One paper included the computer code used for data cleaning in the Supplement (20), which made the data cleaning potentially reproducible.

The information about data cleaning was reported in Methods $(n=5)$, Discussion $(n=3)$ or Supplement $(n=4)$.

\section{Data Screening}

Data screening examines data properties that do not touch the research questions but may affect planned analyses and interpretation (3). This includes a systematic review of the distribution of variables and missing data. Understanding associations between variables can support decisions about modeling and later interpretation of the results. Statements about data screening were grouped by outcome and non-outcome variables and by location in the papers (TABLE 3). Methods of descriptions could include quantitative or graphical data summaries.

A common aspect of data screening is the description of non-outcome variables. These were presented in all articles, commonly in the Results section $(n=24)$ but also in the Supplement $(n=15)$ and occasionally in Methods $(n=5)$. Most articles reported this information in tables $(n=21)$ and text $(n=20)$. Data visualizations were rarely used $(n=2)$. The statistical methods used to describe non-outcome variables were reported in 19 articles. Information about the association between non-outcome variables was included in 14 papers (56\%). Information on missing values for non-outcome variables was reported in 19 
papers (76\%). The information appeared most often in Results $(n=12)$ but also in Methods and in the Supplement ( $\mathrm{n}=6$ each). Ten papers provided information about distributions of non-outcome variables, which later implied a change in analysis plan. This information was provided in Results $(n=4)$, Methods $(n=4)$ and in the Supplement $(n=2)$. This referred mainly to categorizing non-outcome numerical variables. Some studies reported categories with small frequencies, which led to a sparser grouping than originally intended $(27,29)$. In one study $(8)$, the adequateness of a non-outcome variable was checked in the IDA. "Comparison of the multilevel model to a non-multilevel model (likelihood-ratio test) indicated a significant clustering effect of testing intensity by facility $(P<.001)$. [...] Therefore, the [observed/expected] ratio for each facility was calculated based on the sum of the individuals from that facility. The facility was categorized into high intensity or low-intensity categories for comparison." (11). However, it remained unclear to which degree the variable definition was preplanned and what the action would have been, if the likelihood ratio test had not been significant.

Data screening statements for outcome variables were included in all articles, and $72 \%(n=18)$ indicated the methods used to describe them. Item missingness was reported in 11 papers (44\%), unit missingness in 15 papers $(60 \%)$.

\section{Changes in the analysis plan}

Eleven papers (44\%) mentioned some changes in the analysis plan. Reported changes referred to missing data treatment, unexpected values, population heterogeneity and aspects related to variable distributions or data properties (TABLE 4). The reporting of such changes could be found in all sections of the paper except in the Introduction.

Changes were described as follows:

1. Due to variable distributions categories of the variables were grouped, or numerical variables were categorized based on findings from IDA.

- "Because few women were underweight (1.2\%), we combined underweight with normal BMI (normal/underweight) and performed a sensitivity analysis excluding the underweight group." (27)

- Chow et al resolved classification problems of patients by using the category with lower value. "If insufficient information was available to distinguish between grades, the lower grade was applied. " (23)

- Gilbert et al observed that "patients had Hospital Frailty Risk Scores ranging from 0 to 99 , but this was heavily skewed to the right" and categorised it using three risk levels (17).

2. Revising the planned statistical model and including additional variables due to unexpected confounding was the result of IDA in some papers.

- In the discussion, Reges et al acknowledged that "There was a higher proportion of low SES among nonsurgical patients after matching. Given the higher mortality among low SES patients 
in general, SES could have been a confounder. This and other potential confounding characteristics were adjusted for in the models." (10)

- Pollack et al adjusted their analysis for potential confounders. "For example, bystander AED shock was more likely to receive bystander CPR, so we adjusted for this covariate in the analysis," acknowledging that obseved differences in survival could not be attributed solely to the type of help recieved by patients (20).

3. Inclusion and exclusion criteria were modified thus leading to a change in the study population due to unexpected values or population heterogeneity.

- Biccard et al substantially relaxed the inclusion criteria as "more than half the countries in our study could not fulfill the protocol requirements for an included sample, and in hindsight these rules were inappropriately strict despite formal acceptance by the national leaders of these requirements before the study began." (13).

- Yu et al exluded from the analyses the "participants from Zhejiang $(n=56,813)$ where heating was rarely reported $(0.6 \%) . "(12)$

4. Methods to handle missing data in the analysis or inclusion/exclusion criteria were updated.

- Snyder et al used multiple imputation for two non-outcome variables for which they had observed more than $5 \%$ missing values. "Two variables, perineural invasion and lymphovascular invasion, had more than $5 \%$ missing values. Multiple imputation by chained equations was used to substitute predicted values for missing values with 20 imputed values." (11)

- Amarenco et al excluded data from some study sites, and performed subgroup analyses, some of which were not prespecified. "Sites with follow-up data on more than $50 \%$ of their enrolled patients at 5 years were selected for the analysis in this report, and all reported results pertain to this selected cohort." (29)

- Zylbersztejn et al used data screening to exclude hospitals with low quality data: "We excluded hospitals with high proportions of missing data or evidence of linkage error to address incomplete recording of risk factors at birth. We included hospitals with more than 500 births a year, with high completeness of recorded birthweight and gestational age, and hospitals where at least half of all deaths were linked to a death certificate", and "We developed criteria for identifying hospitals with high completeness of gestational age and birth weight, and high quality of linkage with ONS mortality data in an iterative process. " (16)

5. Other data properties may influence statistical models.

- Wood et al exluded from combined analyses of several data sources "studies with fewer than five incident cases of a particular outcome" to avoid model overfitting (14).

Sensitivity analyses 
Sensitivity analyses are commonly used when checking on robustness of models and conclusions. These are often pre-planned in the study design phase, but could be a consequence of IDA and planned before the main analyses instead of having to rely on post hoc analyses. For example,

- "Because few women were underweight (1.2\%), we combined underweight with normal BMI (normal/underweight) and performed a sensitivity analysis excluding the underweight group." (27)

- Inclusion criteria were relaxed during the data collection process and it was noted that "Before analysis we therefore decided to present the data describing the full cohort, and include a perprotocol analysis of the predefined representative sample for comparison." (13)

- "Event rates were estimated among the overall study sample (main analysis), among patients evaluated by a stroke specialist within 24 hours after symptom onset (prespecified sensitivity analysis), and among patients from the 33 sites with follow-up data on more than $80 \%$ of their patients at 5 years (post hoc sensitivity analysis)" (29)

We point out that it was sometimes difficult to decide whether an information about a certain action reflected a consequence of IDA or had been preplanned. For example, the statement "If insufficient information was available to distinguish between grades, the lower grade was applied." (23) may reflect a rule developed during IDA, but it may also reflect a rule already decided on in the study protocol.

\section{Discussion}

Our aim was to describe current practice of reporting in observational studies in highly ranked medical journals. A total of 25 papers about observational studies from five journals (Circulation, JAMA, JCO, Lancet, NEJM) were reviewed. The selected papers included data from disease registries, health insurance data bases, or electronic health records from single or multiple hospitals and cohort studies. To separate IDA from the planned statistical analyses, the research aim for each article was identified as the first step in the review.

This literature review shows that there is only a fragmented reporting of IDA. Only $40 \%$ of the articles included a statement on data cleaning. Such statements could be found in the methods or results section, or in the supplement. Only one paper made the data cleaning process reproducible by providing computer code. In contrast, in genomic studies, reporting of data cleaning is standard practice, e.g. call rate, criteria for linkage disequilibrium, sample quality, and how many samples or variables are excluded during this process (33). An inspection of the data sources of the studies revealed that many studies did not perform a primary data collection but were based on analyzing existing data. This may limit the need to conduct IDA as part of the current study as parts of the IDA may have been completed prior to the study and may hence decrease the likelihood of reporting on IDA in the paper. However, when no information about data cleaning is given, the reader is unsure whether the authors have assured themselves of all relevant data properties. Ideally, authors should report, what percentage of data needed corrections or a confirmative that no major data cleaning was needed. 
Some of the recommendations in the STROBE statement, related to data screening, were included in all articles, such as a description of the characteristics of study participants and summarizing outcome events or follow-up times. While all articles included a table or a description of participant characteristics, sometimes with additional information in the supplement, there were few comments on whether these findings conformed to expectations about the population. Only $76 \%$ of the papers reported item missingness. Some variables of interest were described for subgroups defined by another variable (this was labeled "association between non-outcome variables" in Table 3). We observed that, other than descriptions of subgroups, there were almost no studies who reported on associations between two covariates in a regression model. Quantifying the strength of associations could be relevant, for example, to support the interpretation of results from these models, or may assist in finding redundancies.

Data description by visualization was uncommon. Numerical variables were often categorized, and sometimes sparse categories were grouped, but it was difficult to infer whether these categorizations were preplanned or a consequence of IDA.

There can be insights from IDA that can lead to changing or appending the analysis plan with additional, planned analyses rather than identifying problems later during the statistical modeling process. For example, IDA may lead to additional sensitivity analyses. This shows how useful IDA can be since such analyses can then be planned before the start of the formal intended statistical analyses. Otherwise they would appear as post hoc analyses performed after seeing the results of the main intended analyses, which would diminish their value.

The placement of IDA statements varied over different sections in the articles. In our review data cleaning, data screening, and updating the analysis plan were found in all sections of the articles except the Introduction. The Discussion typically included a paragraph on limitations where some statements could be interpreted as conclusions of data screening.

A systematic process for IDA and its reporting is lacking (3). Such a process and clear reporting of the findings would help to understand the potential shortcomings of a dataset, such as missing values, or subgroups with small sample sizes, or shortcomings in the collection process, and to evaluate the impact of these shortcomings on the research results. A clear reporting of findings is also relevant when making datasets available to other researchers. Initial data analyses can provide valuable insights into the suitability of a data set for a future research study $(34,35)$.

\section{LIMITATIONS}

There are limitations to this study. First, this systematic review was limited to 25 papers in medical journals. However, this was a qualitative study providing examples across five medical journals how IDA is reported and a discussion on how reporting might be improved. and we did not find differences in reporting between the journals. Second, IDA in studies based on disease registries, large electronic health record data bases, or population cohorts may have been performed prior to the study leading to less IDA reporting. Third, it was difficult to determine whether analyses were preplanned or were part of IDA. To 
alleviate this problem there were two reviewers for each article, and one person reviewed all articles to make sure criteria were consistently applied.

\section{Conclusions}

Reporting of initial data analyses in research publications is sparse, and statements on IDA are located throughout the research articles, illustrating the lack of any systematic reporting of IDA.

Recommendations to improve the current poor practice can be made, but a full consensus of what should be expected of IDA reporting needs to be developed. Challenges exist for multi-purpose studies, combining different data sources, or reusing existing data (3)

We present some thoughts towards how IDA reporting could be improved in TABLE 5.

Following these recommendations would be an important step into a more transparent and systematic reporting of analyses which are so often hidden.

\section{Declarations}

\section{Ethics approval and consent to participate}

Not applicable

\section{Consent for publication}

Not applicable

\section{Competing interests}

The authors declare that they have no competing interests.

\section{Funding}

There was no funding for this research.

\section{AUTHOR INFORMATION}

\section{Affiliations}

Department of Statistics and Probability, Michigan State University, East Lansing, MI, USA

Marianne Huebner

Institute of Medical Biometry and Epidemiology, University Medical Center, Hamburg, Germany

Marianne Huebner 
Werner Vach

Department of Clinical Epidemiology and Department of Biomedical Data Sciences Leiden University Medical Center, Leiden, The Netherlands

Saskia le Cessie

Institute for Community Medicine, SHIP-KEF University Medicine of Greifswald, Greifswald, Germany

Carsten Schmidt

Department of Mathematics, Faculty of Mathematics, Natural Sciences and Information Technology, University of Primorksa, Koper, Slovenia

Lara Lusa

\section{Contributions}

The study design was discussed by all authors via conference calls. MH and LL prepared the online submission form, piloted, and refined it prior to use. All authors (MH, WV, CS, SL, LL) participated in the data extraction, the analysis, and interpretation. The initial draft of the manuscript was prepared by $\mathrm{MH}$ and LL. All authors participated in the writing of the manuscript and approved the final version.

\section{Corresponding author}

Marianne Huebner

\section{Acknowledgements}

We are grateful to Edith Motschall, Medical University of Freiburg, for her help with the PubMed electronic database search.

This work was developed as part of the international initiative of Strengthening Analytical Thinking for Observational Studies (STRATOS). The objective of STRATOS is to provide accessible and accurate guidance in the design and analysis of observational studies (http://stratos-initiative.org/). Members of the Topic Group Initial Data Analysis of the STRATOS Initiative are Dianne Cook (Australia), Marianne Huebner (USA), Saskia le Cessie (Netherlands), Lara Lusa (Slovenia), Carsten Oliver Schmidt (Germany), Werner Vach (Switzerland).

\section{Availability of data and materials}

We provided as supplementary information the data collection form (Additional file 1) and PubMed search terms (Additional file 2). 


\section{Abbreviations}

IDA: Initial Data Analysis

PRISMA: Preferred Reporting Items for Systematic Reviews and Meta-Analyses

STROBE: Strengthening the Reporting of Observational Studies in Epidemiology

STRATOS: Strengthening Analytical Thinking for Observational Studies

\section{References}

1. Ioannidis JPA. Why Most Published Research Findings Are False. PLOS Med. 2005 Aug 30;2(8):e124.

2. Leek JT, Peng RD. Statistics: P values are just the tip of the iceberg. Nature. 2015 Apr 28;520(7549):612-612.

3. Huebner M, le Cessie S, Schmidt C, Vach W. A Contemporary Conceptual Framework for Initial Data Analysis. Obs Stud. 2018 Apr 12;4:171-92.

4. Wasserstein RL, Schirm AL, Lazar NA. Moving to a World Beyond " $p<0.05$." Am Stat. 2019 Mar 29;73(sup1):1-19.

5. Ioannidis JPA. What Have We (Not) Learnt from Millions of Scientific Papers with P Values? Am Stat. 2019 Mar 29;73(sup1):20-5.

6. Wang SV, Schneeweiss S, Berger ML, Brown J, de Vries F, Douglas I, et al. Reporting to Improve Reproducibility and Facilitate Validity Assessment for Healthcare Database Studies V1.0.

Pharmacoepidemiol Drug Saf. 2017;26(9):1018-32.

7. Vandenbroucke JP, von Elm E, Altman DG, Gøtzsche PC, Mulrow CD, Pocock SJ, et al. Strengthening the Reporting of Observational Studies in Epidemiology (STROBE): explanation and elaboration. PLoS Med. 2007 Oct 16;4(10):e297.

8. Inohara T, Xian Y, Liang L, Matsouaka RA, Saver JL, Smith EE, et al. Association of Intracerebral Hemorrhage Among Patients Taking Non-Vitamin K Antagonist vs Vitamin K Antagonist Oral Anticoagulants With In-Hospital Mortality. JAMA. 2018 06;319(5):463-73.

9. Purnell TS, Luo X, Cooper LA, Massie AB, Kucirka LM, Henderson ML, et al. Association of Race and Ethnicity With Live Donor Kidney Transplantation in the United States From 1995 to 2014. JAMA. 2018 02;319(1):49-61.

10. Reges O, Greenland P, Dicker D, Leibowitz M, Hoshen M, Gofer I, et al. Association of Bariatric Surgery Using Laparoscopic Banding, Roux-en-Y Gastric Bypass, or Laparoscopic Sleeve Gastrectomy vs Usual Care Obesity Management With All-Cause Mortality. JAMA. 2018 16;319(3):279-90.

11. Snyder R, Hu C-Y, Cuddy A, Francescatti AB, Schumacher JR, Van Loon K, et al. Association Between Intensity of Post-Treatment Surveillance Testing, Detection of Recurrence, and Survival in Patients with Stage I-III Colorectal Cancer (AFT-02). JAMA. 2018 May 22;319(20):2104-15. 
12. Yu K, Qiu G, Chan K-H, Lam K-BH, Kurmi OP, Bennett DA, et al. Association of Solid Fuel Use With Risk of Cardiovascular and All-Cause Mortality in Rural China. JAMA. 2018 Apr 3;319(13):1351-61.

13. Biccard BM, Madiba TE, Kluyts H-L, Munlemvo DM, Madzimbamuto FD, Basenero A, et al. Perioperative patient outcomes in the African Surgical Outcomes Study: a 7-day prospective observational cohort study. Lancet Lond Engl. 2018 21;391(10130):1589-98.

14. Wood AM, Kaptoge S, Butterworth AS, Willeit P, Warnakula S, Bolton T, et al. Risk thresholds for alcohol consumption: combined analysis of individual-participant data for 599912 current drinkers in 83 prospective studies. The Lancet. 2018 Apr 14;391(10129):1513-23.

15. Dziadzko V, Clavel M-A, Dziadzko M, Medina-Inojosa JR, Michelena H, Maalouf J, et al. Outcome and undertreatment of mitral regurgitation: a community cohort study. The Lancet. $2018 \mathrm{Mar}$ 10;391(10124):960-9.

16. Zylbersztejn A, Gilbert R, Hjern A, Wijlaars L, Hardelid P. Child mortality in England compared with Sweden: a birth cohort study. The Lancet. 2018 May 19;391(10134):2008-18.

17. Gilbert T, Neuburger J, Kraindler J, Keeble E, Smith P, Ariti C, et al. Development and validation of a Hospital Frailty Risk Score focusing on older people in acute care settings using electronic hospital records: an observational study. Lancet Lond Engl. 2018 05;391(10132):1775-82.

18. Alexander PMA, Nugent AW, Daubeney PEF, Lee KJ, Sleeper LA, Schuster T, et al. Long-Term Outcomes of Hypertrophic Cardiomyopathy Diagnosed During Childhood: Results From a National Population-Based Study. Circulation. 2018 Jul 3;138(1):29-36.

19. Nazerian P, Mueller C, Soeiro A de M, Leidel BA, Salvadeo SAT, Giachino F, et al. Diagnostic Accuracy of the Aortic Dissection Detection Risk Score Plus D-Dimer for Acute Aortic Syndromes: The ADvISED Prospective Multicenter Study. Circulation. 2018 16;137(3):250-8.

20. Pollack RA, Brown SP, Rea T, Aufderheide T, Barbic D, Buick JE, et al. Impact of Bystander Automated External Defibrillator Use on Survival and Functional Outcomes in Shockable Observed Public Cardiac Arrests. Circulation. 2018 15;137(20):2104-13.

21. Puelacher C, Lurati Buse G, Seeberger D, Sazgary L, Marbot S, Lampart A, et al. Perioperative Myocardial Injury After Noncardiac Surgery: Incidence, Mortality, and Characterization. Circulation. 2018 20;137(12):1221-32.

22. Chao T-F, Liu C-J, Lin Y-J, Chang S-L, Lo L-W, Hu Y-F, et al. Oral Anticoagulation in Very Elderly Patients With Atrial Fibrillation: A Nationwide Cohort Study. Circulation. 2018 Jul 3;138(1):37-47.

23. Chow EJ, Chen Y, Hudson MM, Feijen EAM, Kremer LC, Border WL, et al. Prediction of Ischemic Heart Disease and Stroke in Survivors of Childhood Cancer. J Clin Oncol. 2017 Nov 2;36(1):44-52.

24. Kenzik KM, Balentine C, Richman J, Kilgore M, Bhatia S, Williams GR. New-Onset Cardiovascular Morbidity in Older Adults With Stage I to III Colorectal Cancer. J Clin Oncol Off J Am Soc Clin Oncol. 2018 20;36(6):609-16.

25. Degnim AC, Winham SJ, Frank RD, Pankratz VS, Dupont WD, Vierkant RA, et al. Model for Predicting Breast Cancer Risk in Women With Atypical Hyperplasia. J Clin Oncol Off J Am Soc Clin Oncol. 2018 Jun 20;36(18):1840-6. 
26. Gundle KR, Kafchinski L, Gupta S, Griffin AM, Dickson BC, Chung PW, et al. Analysis of Margin Classification Systems for Assessing the Risk of Local Recurrence After Soft Tissue Sarcoma Resection. J Clin Oncol Off J Am Soc Clin Oncol. 2018 01;36(7):704-9.

27. Clarke MA, Fetterman B, Cheung LC, Wentzensen N, Gage JC, Katki HA, et al. Epidemiologic Evidence That Excess Body Weight Increases Risk of Cervical Cancer by Decreased Detection of Precancer. J Clin Oncol Off J Am Soc Clin Oncol. 2018 Apr 20;36(12):1184-91.

28. Hoen B, Schaub B, Funk AL, Ardillon V, Boullard M, Cabié A, et al. Pregnancy Outcomes after ZIKV Infection in French Territories in the Americas. N Engl J Med. 2018 Mar 15;378(11):985-94.

29. Amarenco P, Lavallée PC, Monteiro Tavares L, Labreuche J, Albers GW, Abboud H, et al. Five-Year Risk of Stroke after TIA or Minor Ischemic Stroke. N Engl J Med. 2018 Jun 7;378(23):2182-90.

30. Calderon-Margalit R, Golan E, Twig G, Leiba A, Tzur D, Afek A, et al. History of Childhood Kidney Disease and Risk of Adult End-Stage Renal Disease. N Engl J Med. 2018 Feb 1;378(5):428-38.

31. Kyle RA, Larson DR, Therneau TM, Dispenzieri A, Kumar S, Cerhan JR, et al. Long-Term Follow-up of Monoclonal Gammopathy of Undetermined Significance. N Engl J Med. 2018 Jan 18;378(3):241-9.

32. Mead PS, Duggal NK, Hook SA, Delorey M, Fischer M, Olzenak McGuire D, et al. Zika Virus Shedding in Semen of Symptomatic Infected Men. N Engl J Med. 2018 Apr 12;378(15):1377-85.

33. Turner S, Armstrong LL, Bradford Y, Carlson CS, Crawford DC, Crenshaw AT, et al. Quality control procedures for genome-wide association studies. Curr Protoc Hum Genet. 2011 Jan;Chapter 1:Unit1.19.

34. Singh KNM, Shetty YC. Data sharing: A viable resource for future. Perspect Clin Res. 2017;8(2):63-7.

35. Anatomy of a Data Note [Internet]. BMC Research Notes; Available from: https://resourcecms.springernature.com/springer-cms/rest/v1/content/16169050/data/v2

\section{Tables}

TABLE 1: Search and selection of articles 


\begin{tabular}{|l|c|c|c|c|c|c|}
\hline & NEJM & JCO & Lancet & JAMA & CIRC & Total \\
\hline Selected papers via Pubmed search & 11 & 63 & 21 & 29 & 68 & 192 \\
\hline $\begin{array}{l}\text { Included according to criteria after reviewing } \\
\text { abstract }\end{array}$ & 7 & 22 & 12 & 19 & 45 & 105 \\
\hline $\begin{array}{l}\text { Included according to criteria after reviewing full text } \\
\text { article }\end{array}$ & 6 & 21 & 10 & 19 & 44 & 100 \\
\hline Randomly selected for review & 5 & 5 & 5 & 5 & 5 & 25 \\
\hline
\end{tabular}

TABLE 2: Characteristics of the included studies 


\begin{tabular}{|c|c|c|c|c|c|}
\hline Study & Journal & Location & $\begin{array}{l}\text { Years of participant } \\
\text { selection* }\end{array}$ & $\begin{array}{l}\text { Study } \\
\text { size* }\end{array}$ & Data source* \\
\hline $\begin{array}{l}\text { Inohara et al } \\
\text { (8) }\end{array}$ & JAMA & USA & $2013-2016$ & 141,311 & Stroke registry \\
\hline $\begin{array}{l}\text { Purnell et al } \\
\text { (9) }\end{array}$ & JAMA & USA & 1995-2014 & 453,162 & Transplant registry \\
\hline $\begin{array}{l}\text { Reges et al } \\
(10)\end{array}$ & JAMA & Israel & 2005-2015 & 33,540 & Multiple hospitals \\
\hline $\begin{array}{l}\text { Snyder et al } \\
\text { (11) }\end{array}$ & JAMA & USA & 2006-2007 & 8,529 & Cancer registry \\
\hline Yu et al (12) & JAMA & China & $2004-2008$ & 271,217 & Nationwide Biobank \\
\hline $\begin{array}{l}\text { Biccard et al } \\
\text { (13) }\end{array}$ & Lancet & 25 African countries & 2016 & 11,422 & Multiple hospitals \\
\hline $\begin{array}{l}\text { Wood et al } \\
(14)\end{array}$ & Lancet & $\begin{array}{l}19 \text { high income } \\
\text { countries }\end{array}$ & $1964-2010$ & 599,912 & $\begin{array}{l}\text { Multiple CVD registries and a } \\
\text { biobank }\end{array}$ \\
\hline $\begin{array}{l}\text { Dziadzko et al } \\
\text { (15) }\end{array}$ & Lancet & USA & $2000-2010$ & 1,294 & $\begin{array}{l}\text { Single hospital and a medical } \\
\text { registry of area residents }\end{array}$ \\
\hline $\begin{array}{l}\text { Zylbersztejn } \\
\text { et al (16) }\end{array}$ & Lancet & UK, Sweden & $2003-2013$ & $4,946,246$ & $\begin{array}{l}\text { Hospital episode registries, birth } \\
\text { and death registries }\end{array}$ \\
\hline $\begin{array}{l}\text { Gilbert et al } \\
\text { (17) }\end{array}$ & Lancet & UK & 2013-2015 & 22,139 & $\begin{array}{l}\text { Hospital episode registry; death } \\
\text { registry }\end{array}$ \\
\hline $\begin{array}{l}\text { Alexander et } \\
\text { al (18) }\end{array}$ & Circulation & Australia & 1987-1996 & 80 & Childhood cardio-myopathy registry \\
\hline $\begin{array}{l}\text { Nazerian et al } \\
\text { (19) }\end{array}$ & Circulation & $\begin{array}{l}\text { Brazil, Germany, Italy, } \\
\text { Switzerland }\end{array}$ & $2014-2016$ & 1,850 & Multiple hospitals \\
\hline $\begin{array}{l}\text { Pollack et al } \\
(20)\end{array}$ & Circulation & USA, Canada & 2011-2015 & 2,500 & Resuscitation outcomes registry \\
\hline $\begin{array}{l}\text { Puelacher et } \\
\text { al (21) }\end{array}$ & Circulation & Switzerland & $2014-2015$ & 2,018 & Single hospital \\
\hline $\begin{array}{l}\text { Chao et al } \\
(22)\end{array}$ & Circulation & Taiwan & 1996-2015 & 32,160 & Health Insurance database \\
\hline $\begin{array}{l}\text { Chow et al } \\
(23)\end{array}$ & $\mathrm{JCO}$ & USA & $1962-2001$ & 13,060 & Multiple hospitals \\
\hline $\begin{array}{l}\text { Kenzik et al } \\
(24)\end{array}$ & $\mathrm{JCO}$ & USA & $2000-2011$ & 72,408 & $\begin{array}{l}\text { Cancer registry and Health } \\
\text { insurance database }\end{array}$ \\
\hline $\begin{array}{l}\text { Degnim et al } \\
(25)\end{array}$ & $\mathrm{JCO}$ & USA & 1967-2001 & 669 & Single hospital \\
\hline $\begin{array}{l}\text { Gundle et al } \\
\text { (26) }\end{array}$ & $\mathrm{JCO}$ & USA & $1989-2014$ & 2,217 & Single hospital \\
\hline $\begin{array}{l}\text { Clarke et al } \\
(27)\end{array}$ & $\mathrm{JCO}$ & USA & $2003-2015$ & 944,227 & Multiple hospitals \\
\hline $\begin{array}{l}\text { Hoen et al } \\
(28)\end{array}$ & NEJM & $\begin{array}{c}\text { French territories in } \\
\text { the Americas }\end{array}$ & 2016 & 555 & ZIKV pregnancy population cohort \\
\hline $\begin{array}{l}\text { Amarenco et } \\
\text { al (29) }\end{array}$ & NEJM & $\begin{array}{l}\text { Europe, Asia, Latin } \\
\text { America }\end{array}$ & $2009-2011$ & 3,356 & Stroke registry \\
\hline $\begin{array}{l}\text { Calderon et al } \\
\text { (30) }\end{array}$ & NEJM & Israel & $1980-2014$ & $1,522,731$ & $\begin{array}{l}\text { Renal registry and population } \\
\text { cohort }\end{array}$ \\
\hline Kyle et al (31) & NEJM & USA & 1960-1994 & 1,384 & Single hospital \\
\hline $\begin{array}{l}\text { Mead et al } \\
(32)\end{array}$ & NEJM & USA & 2016-2017 & 184 & ZIKV male population cohort \\
\hline
\end{tabular}

*Only the development sample size (i.e not the validation sample size) was included here or the population of main interest for the analysis (i.e. not matched populations) 
TABLE 3. Number of papers with data screening statements by location in the paper.

\begin{tabular}{|c|c|c|c|c|c|}
\hline & & \multicolumn{4}{|c|}{ Location in Paper } \\
\hline & Mentioned in papers, $\mathrm{n}(\%)$ & $\bar{M}$ & $\mathbf{R}$ & D & $\mathrm{S}$ \\
\hline Description of non-outcome variables & $25(100 \%)$ & 5 & 24 & 0 & 15 \\
\hline Description of missing values of non-outcome variables & $19(76 \%)$ & 6 & 12 & 0 & 6 \\
\hline Reporting association between non-outcome variables & $14(56 \%)$ & 5 & 6 & 0 & 5 \\
\hline Description of non-outcome variables for subgroups & $21(84 \%)$ & 2 & 19 & 1 & 11 \\
\hline Description of transformation of non-outcome variables & $10(40 \%)$ & 4 & 4 & 0 & 2 \\
\hline Description of outcome variable(s) & $25(100 \%)$ & 2 & 25 & 0 & 9 \\
\hline Information of missing values for outcome variables & $12(48 \%)$ & 3 & 7 & 3 & 4 \\
\hline Description of methods for outcome variables & $19(76 \%)$ & 13 & 4 & 0 & 1 \\
\hline Description of missingness of subjects & $15(60 \%)$ & 1 & 11 & 2 & 5 \\
\hline Description of transformations in outcome variables & $7(28 \%)$ & 1 & 6 & 0 & 0 \\
\hline
\end{tabular}

Abbreviations: M-methods, R-results, D- discussion, S-supplement

TABLE 4. Number of papers with changes of the analysis plan statements by location in the paper. 


\begin{tabular}{|c|c|c|c|c|c|} 
& & \multicolumn{4}{|c|}{ Location in Paper } \\
\hline Reasons for change & Number of papers, $\mathbf{n}(\%)$ & M & R & D & S \\
& & & & & \\
\hline Unexpected Values & $2(8 \%)$ & 2 & 0 & 1 & 0 \\
\hline Heterogeneity & $1(4 \%)$ & 0 & 1 & 0 & 0 \\
\hline Unexpected confounding & $2(8 \%)$ & 1 & 1 & 2 & 0 \\
\hline Variable Distribution & $4(16 \%)$ & 3 & 1 & 1 & 0 \\
\hline Other Data Properties & $2(8 \%)$ & 2 & 0 & 0 & 0 \\
\hline Missing Data & $5(20 \%)$ & 4 & 1 & 1 & 0 \\
\hline
\end{tabular}

Abbreviations: M-methods, R-results, D- discussion, S-supplement

Table 5: Recommendations for reporting practice for initial data analyses

\begin{tabular}{|l|l|l|}
\hline & $\begin{array}{l}\text { Current reporting } \\
\text { practice }\end{array}$ & Recommendations for improved reporting practice \\
\hline 1 & $\begin{array}{l}\text { Information on IDA is } \\
\text { sparse and may suffer } \\
\text { from selective reporting }\end{array}$ & $\begin{array}{l}\text { Full reporting of relevant results as supplementary material and } \\
\text { reporting of all results with impact on analysis/interpretation in the } \\
\text { paper }\end{array}$ \\
\hline 2 & $\begin{array}{l}\text { Information on IDA can } \\
\text { be found in all sections } \\
\text { of a paper. }\end{array}$ & $\begin{array}{l}\text { IDA methodology to be described in Methods; } \\
\text { IDA results to be described in Methods or Results; }\end{array}$ \\
\hline 3 & $\begin{array}{l}\text { Iistinction between pre- } \\
\text { planned decisions and } \\
\text { IDA-driven decisions are } \\
\text { unclear. }\end{array}$ & $\begin{array}{l}\text { Pre-planned decisions should be reported in Methods; IDA driven } \\
\text { alterations of the analysis plan should be reported with motivation in } \\
\text { Methods. }\end{array}$ \\
\hline 4 & $\begin{array}{l}\text { Characteristics of } \\
\text { participants are listed } \\
\text { without comments. }\end{array}$ & $\begin{array}{l}\text { Participants' characteristics should be checked for consistency with } \\
\text { expectations and for potential impact on analysis and interpretation. At } \\
\text { a minimum a statement should be included to confirm no violated } \\
\text { expectations. }\end{array}$ \\
\hline 5 & $\begin{array}{l}\text { Reporting on } \\
\text { missingness is } \\
\text { incomplete. }\end{array}$ & $\begin{array}{l}\text { Full reporting of missingness, e.g. a flow chart describes unit } \\
\text { missingness and a table for item missingness of variables }\end{array}$ \\
\hline 6 & $\begin{array}{l}\text { Associations among } \\
\text { variables are not } \\
\text { reported. }\end{array}$ & $\begin{array}{l}\text { Associations not involving the research question but with potential } \\
\text { impact on interpretation of results should be reported }\end{array}$ \\
\hline
\end{tabular}

\section{Figures}




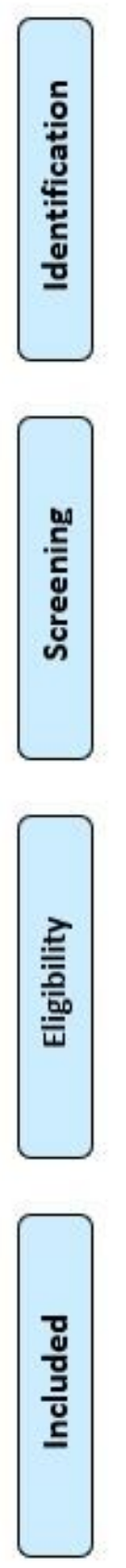

$$
\begin{aligned}
& \text { Articles identified through PubMed } \\
& \text { database searching } \\
& (n=192)
\end{aligned}
$$
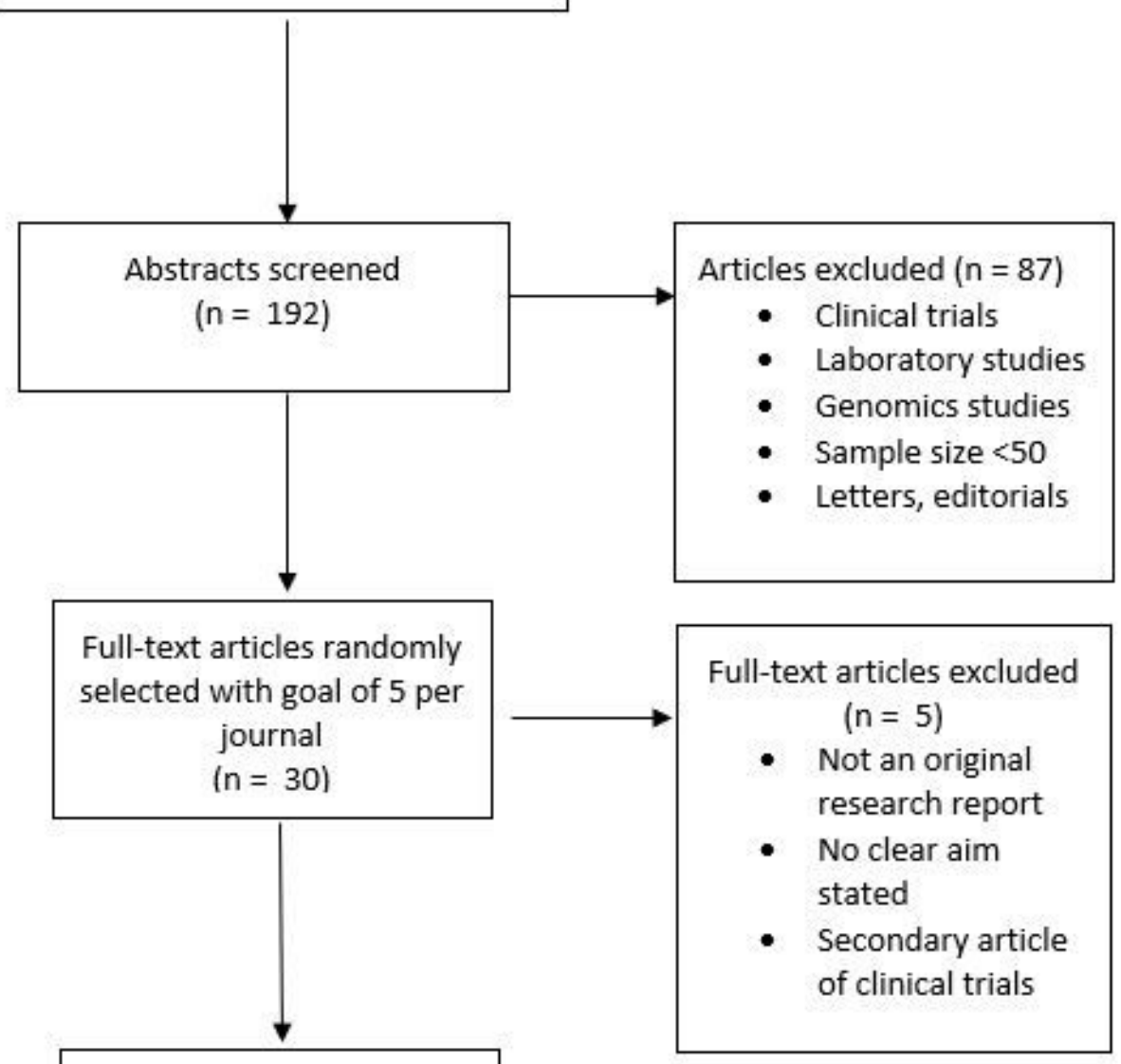

Studies included

$(n=25)$

\section{Figure 1}

Flow Diagram for Initial Data Analysis reporting

\section{Supplementary Files}

This is a list of supplementary files associated with this preprint. Click to download.

- PRISMAchecklistIDA.doc

- PubMedSearch.docx 
- DataCollectionForm20181129.docx 